\title{
Karnofsky Performance Status 90
}

National Cancer Institute

\section{Source}

National Cancer Institute. Karnofsky Performance Status 90. NCI Thesaurus. Code C105709.

Able to carry on normal activity; minor signs or symptoms of disease. 